\title{
Treatment of Pediatric Chronic Kidney Disease-Mineral and Bone Disorder
}

\author{
Mark R. Hanudel, M.D., M.S. and Isidro B. Salusky, M.D. \\ Department of Pediatrics, David Geffen School of Medicine at UCLA, Los Angeles, CA
}

\begin{abstract}
a) Purpose of review-In this paper, we review the pathogenesis and treatment of chronic kidney disease-mineral and bone disorder (CKD-MBD), especially as it relates to pediatric CKD patients.
\end{abstract}

b) Recent findings-Disordered regulation of bone and mineral metabolism in CKD may result in fractures, skeletal deformities, and poor growth, which is especially relevant for pediatric CKD patients. Moreover, CKD-MBD may result in extra-skeletal calcification and cardiovascular morbidity. Early increases in fibroblast growth factor 23 (FGF23) levels play a key, primary role in CKD-MBD pathogenesis. Therapeutic approaches in pediatric CKD-MBD aim to minimize complications to the growing skeleton and prevent extra-skeletal calcifications, mainly by addressing hyperphosphatemia and secondary hyperparathyroidism. Ongoing clinical trials are focused on assessing the benefit of FGF23 reduction in CKD.

c) Summary-CKD-MBD is a systemic disorder that has significant clinical implications. Treatment of CKD-MBD in children requires special consideration in order to maximize growth, optimize skeletal health, and prevent cardiovascular disease.

\section{Keywords}

Chronic Kidney Disease; CKD-Mineral and Bone Disorder; Children; Pathogenesis; Treatment of CKD-MBD

\section{Pediatric Chronic Kidney Disease-Mineral and Bone Disorder}

In pediatric patients with chronic kidney disease (CKD), disordered regulation of bone and mineral metabolism may be especially detrimental, resulting in fractures, skeletal deformities, and, most pertinently, poor growth. Such disordered regulation may be

\footnotetext{
Address Correspondence to: Mark R. Hanudel, M.D., M.S., Division of Pediatric Nephrology, David Geffen School of Medicine at UCLA, 10833 Le Conte Avenue, MDCC A2-383, Los Angeles, CA 90095-1752, Phone: 310-206-6987, Fax: 310-825-0442, mhanudel@mednet.ucla.edu.

Compliance with Ethical Guidelines

Conflict of Interest

Mark Hanudel declares no conflict of interest.

Isidro Salusky reports grants from Amgen, grants from Abbvie, and serving on an advisory board from OPTKO, outside the submitted work.

Human and Animal Rights and Informed Consent

This article does not contain any studies with human or animal subjects performed by any of the authors.
} 
characterized by abnormalities in phosphate, calcium, parathyroid hormone (PTH), calcitriol (1,25-dihydroxyvitamin D3, or 1,25D), and/or fibroblast growth factor 23 (FGF23) metabolism, that lead to the different subtypes of renal osteodystrophy. The term "renal osteodystrophy" specifically refers to alterations in bone morphology associated with CKD, which can be characterized by the histomorphometric parameters of bone turnover, mineralization, and volume (1). Traditionally, the different types of renal osteodystrophy have been classified on the basis of bone turnover and mineralization (2). Both osteitis fibrosa and mixed disease are characterized by increased turnover, but osteitis fibrosa has normal mineralization, whereas mixed disease has abnormal mineralization. Both osteomalacia and adynamic disease are characterized by decreased turnover, with abnormal mineralization in osteomalacia and acellularity in adynamic disease. Renal osteodystrophy is one measure of the skeletal component of the systemic disorder termed CKD-mineral and bone disorder (CKD-MBD). CKD-MBD describes a broader clinical syndrome that develops as a systemic disorder of mineral and bone metabolism due to CKD, which is manifested by abnormalities in bone and mineral metabolism and/or extra-skeletal calcification (1).

In children, growth is one of the most important markers of health, as well as one of the most vital clinical outcome measures. Contributed to by renal osteodystrophy, and more broadly CKD-MBD, children with CKD do not grow well. In a cross-sectional study of 5615 pediatric CKD patients included in the North American Pediatric Renal Trials and Collaborative Studies (NAPRTCS) chronic renal failure registry, Seikaly et al assessed the percentages of subjects with short stature, defined as a height standard deviation score of less than -1.88 (equivalent to less than the third percentile) (3). Overall, $37 \%$ of subjects had short stature, including $22 \%$ of those with an estimated glomerular filtration rate (eGFR) of $50-75 \mathrm{ml} / \mathrm{min} / 1.73 \mathrm{~m}^{2}, 38 \%$ of those with an eGFR of $25-50 \mathrm{ml} / \mathrm{min} / 1.73 \mathrm{~m}^{2}, 47 \%$ of those with an eGFR of $10-25 \mathrm{ml} / \mathrm{min} / 1.73 \mathrm{~m}^{2}$, and $68 \%$ of those with an eGFR of $<10 \mathrm{ml} / \mathrm{min} /$ $1.73 \mathrm{~m}^{2}$.

Besides poor linear growth, children with CKD also experience bone-specific morbidity secondary to renal osteodystrophy, including fractures and bone deformities. In a prospective study of 537 pediatric CKD patients included in the CKD in Children (CKiD) cohort, Denburg et al evaluated the incidence of fractures (4). At enrollment, the median age was 11.0 years (interquartile range [IQR] 7.4, 14.5 years); the median eGFR was $47[34,59]$ $\mathrm{ml} / \mathrm{min} / 1.73 \mathrm{~m}^{2}$; and the median duration of CKD was $8.5[4.4,12.9]$ years. $16 \%$ of subjects reported a prior history of fracture. Over a median follow-up of 3.9 [1.8, 4.9] years, 67 participants $(12.5 \%)$ reported an incident fracture. The gender-specific fracture rates in this cohort were 2- to 3-fold higher than published general population rates. Because of altered skeletal remodeling, bone deformities are also common in pediatric CKD patients. Renal osteodystrophy may clinically manifest as slipped epiphyses of the femur, humerus, radius, and/or ulna, resulting not only in skeletal deformities, but also pain, abnormal gait, and/or inability to ambulate (5). Genu valgum, genu varum, and pes varus may also occur and, importantly, may persist despite long-term treatment with active vitamin D sterols.

To assess the prevalence of renal osteodystrophy in the pediatric end-stage renal disease (ESRD) population, Bakkaloglu et al evaluated bone histomorphometry in 161 pediatric 
dialysis patients (mean age $14.1 \pm 1.2$ years) in whom active vitamin D sterol therapy was held for four weeks prior to bone biopsy (6). Using the TMV (turnover, mineralization, volume) classification system, $57 \%$ had high bone turnover, $39 \%$ had normal bone turnover, and $4 \%$ had low bone turnover. Abnormal mineralization, defined by a concurrent increase in osteoid volume and osteoid maturation time, was present in $48 \%$ of all subjects, including $58 \%$ of those with high bone turnover, $38 \%$ of those with normal bone turnover, and $29 \%$ of those with low bone turnover. Bone volume was normal in $73 \%$ of subjects and increased in $27 \%$. Such high rates of abnormal mineralization were also observed in a subsequent study of 60 pediatric dialysis patients, in which $80 \%$ of subjects had defective mineralization, despite treatment with active vitamin D sterols (7).

To assess the prevalence of renal osteodystrophy in the pediatric pre-dialysis population, Wesseling-Perry et al evaluated bone histomorphometry in 52 pediatric non-dialysis patients with CKD stages $2-5$ (mean age $12.2 \pm 5.2$ years) (8). Bone turnover was normal in all subjects with CKD stage 2, but was increased in $13 \%$ with CKD stage 3 and in $29 \%$ with CKD stage 4/5. Only four subjects in the entire cohort (8\%) had decreased bone turnover. On the other hand, abnormal mineralization, defined by a concurrent increase in osteoid volume and osteoid maturation time, was present in $29 \%$ of subjects with CKD stage 2, $42 \%$ with CKD stage 3, and $79 \%$ with CKD stage $4 / 5$. Bone volume was normal or increased in $96 \%$ of the entire cohort. This study demonstrated that mineralization defects are the first observed skeletal abnormalities in children with CKD, and that the prevalence of abnormal mineralization and turnover increases with CKD progression. In dialysis patients, such mineralization defects persist despite active vitamin $\mathrm{D}$ sterol therapy and may play a role in the pathogenesis of fractures and skeletal deformities.

Whereas bone biopsy is the gold standard for evaluating bone turnover and mineralization, bone quality (structure) may be better assessed with imaging. In adults, dual-energy x-ray absorptiometry (DXA) scans are commonly used to assess bone mineral density. However, in children with CKD, DXA scans have significant limitations, as described by Weber and Mehls (9) and by Bacchetta et al (10). Specifically, DXA scans rely on areal rather than volumetric bone mineral density, resulting in an artificial underestimation of bone density in short people (including growth delayed pediatric CKD patients). Also, DXA scans cannot distinguish between cortical and trabecular bone, which may be differentially affected in CKD. Lastly, DXA scans cannot evaluate trabecular microarchitecture, which is a significant determinant of bone quality. Therefore, some recommend against the use of DXA scans in children with CKD (9). Also, as noted above, when assessed by bone histomorphometry, most pediatric CKD patients have normal or high bone volume. Even so, regarding bone health in children and adolescents with chronic diseases that may affect the skeleton, the International Society for Clinical Densitometry (ISCD) pediatric task force recommends that, "In patients with primary bone disease or at risk for secondary bone disease, a DXA should be performed when the patient may benefit from interventions to decrease their elevated risk of a clinically significant fracture, and the DXA results will influence that management" (11). Whether this recommendation is specifically applicable to children with CKD remains to be determined. 
Other imaging modalities used to assess bone mineral content in children include quantitative computed tomography (QCT), peripheral quantitative computed tomography (pQCT), and quantitative ultrasonography (12). QCT assesses the volume and density of bone in both the axial and appendicular skeleton; however, it's clinical value is limited by cost, radiation exposure, and lack of standardization. pQCT is more readily available and involves less radiation exposure. pQCT bone mineral density measurements correlate with circulating mineral metabolism factors, including $\mathrm{PTH}$, in pediatric CKD patients $(13,14)$. The ISCD pediatric task force recommends that $\mathrm{pQCT}$ "can be used clinically in children where appropriate reference data and expertise are available" (11). Quantitative ultrasonography is easy to perform, does not involve radiation exposure, and has been shown to diagnose secondary hyperparathyroidism better than DEXA in children with CKD (15); however, the results generated may be difficult to apply clinically. Moreover, there remains a paucity of studies assessing the impact of these imaging techniques in children with CKD, and studies that define the associations between these imaging results and bone histology are needed.

\section{Pathogenesis of CKD-MBD}

CKD-MBD pathogenesis involves a complex interplay among the kidney, bone, and parathyroid glands. As functional nephrons are lost and GFR declines, a cascade of maladaptive events develops that results in bone disease, extra-skeletal calcification, and adverse cardiovascular outcomes. Different factors have been implicated in the pathogenesis of this maladaptive response, but the primary trigger remains to be defined. In the early stages of CKD, FGF23 levels increase while phosphate and PTH remain within normal ranges $(16,17)$. With progression of CKD, phosphate retention increases levels of phosphaturic hormones FGF23 $(18,19)$ and PTH $(20)$; decreases 1,25D levels $(20)$ in order to lessen enteral phosphate absorption; and decreases ionized calcium levels via increased binding. Elevated FGF23 levels further decrease 1,25D levels via renal 1a-hydroxylase suppression (21) and 24-hydroxylase induction (22). Decreased 1,25D levels reduce intestinal calcium absorption, and low 1,25D and low ionized calcium both further increase PTH levels, resulting in secondary hyperparathyroidism (23). Although different experimental models of CKD have demonstrated increases in FGF23 before PTH, recently published data seem to challenge the concept of primary increases in FGF23 levels. In a large cohort of over 1000 adults, with generally normal kidney function (99\% with eGFR $>60 \mathrm{ml} / \mathrm{min} / 1.73 \mathrm{~m}^{2}$ ), Dhayat et al observed that PTH levels began to increase when eGFR decreased below $126 \mathrm{ml} / \mathrm{min} / 1.73 \mathrm{~m}^{2}$, whereas FGF23 levels only began to increase when eGFR decreased below $102 \mathrm{ml} / \mathrm{min} / 1.73 \mathrm{~m}^{2}$ (24). Although further research is needed to better define the complex relationship among GFR, FGF23, PTH, and 1,25D (25), regardless of the initial sequence of events, FGF23 and PTH levels increase with CKD progression. Increased PTH activity on bone results in increased bone turnover and resorption, which weakens bones and increases both calcium and phosphate, which may promote vascular calcification (26).

In addition to renal phosphate retention contributing to multi-organ adverse effects and precipitating CKD-MBD, primary kidney injury/repair mechanisms may produce circulating factors that directly affect the vasculature, the myocardium, and the skeleton (27). 
Specifically, local kidney repair mechanisms involving Wnt (Wingless-related integration site) signaling pathway reactivation produce autoregulatory Wnt inhibitors, including Dickkopf-1 (Dkk1) and sclerostin (27). In animal models of early CKD, increased circulating levels of such Wnt inhibitors were observed in the circulation, with concomitant decreased bone formation rates and vascular calcification; Dkk1 neutralization increased bone formation rates and decreased vascular calcification, demonstrating the effect of circulating Wnt inhibitors on CKD-MBD pathogenesis (28).

\section{Therapeutic approaches in CKD-MBD}

Current pediatric renal osteodystrophy treatment paradigms aim to minimize complications to the growing skeleton and prevent the extraskeletal calcifications that define CKD-MBD. Therapeutic approaches focus on the treatment of hyperphosphatemia and secondary hyperparathyroidism.

\section{Hyperphosphatemia}

In the pediatric population, the normal ranges of serum phosphate vary substantially by age. In the first six months of life, normal serum phosphate concentrations range from 5.2-8.4 $\mathrm{mg} / \mathrm{dL}$, decreasing to $5.0-7.8 \mathrm{mg} / \mathrm{dL}$ during the second six months of life, then $4.5-6.5$ $\mathrm{mg} / \mathrm{dL}$ at ages $1-5$ years, then $3.6-5.8 \mathrm{mg} / \mathrm{dL}$ at ages $6-12$ years, then $2.3-4.5 \mathrm{mg} / \mathrm{dL}$ in adolescents (ages 13-20 years) (29). In healthy children and in children with CKD, serum phosphate concentrations exhibit circadian variation, decreasing after breakfast, nadiring in the late morning, then increasing in the early afternoon (30). In pediatric CKD patients with serum phosphate levels above range for age, dietary phosphorus restriction is required. In infants, adequate intake (AI) of phosphorus is $100 \mathrm{mg}$ daily for ages $0-6$ months, and 275 mg daily for ages 7-12 months (29). The recommended dietary allowances (RDA) for older children are: $460 \mathrm{mg}$ daily for ages $1-3$ years, $500 \mathrm{mg}$ daily for ages $4-8$ years, and $1250 \mathrm{mg}$ daily for ages 9-18 years (29). In children with CKD stages 3-5 and 5D, when the serum PTH concentration is above the target range for CKD stage (see below) and the serum phosphate concentration exceeds the normal reference range for age, it is suggested that dietary phosphorus intake be reduced to $80 \%$ of the AI or RDA (29). After initiation of dietary phosphorus restriction, it is suggested that serum phosphate concentration be monitored at least every 3 months in children with CKD stages 3 to 4 and monthly in children with CKD stage 5 and 5D (29).

Persistent hyperphosphatemia despite dietary phosphorus restriction necessitates the use of phosphate-binding agents. Enteral binders complex with phosphorus in the intestinal tract, limiting phosphorus absorption by blocking passive diffusion across a paracellular gradient. Calcium-based phosphate binders are widely prescribed and are effective in lowering serum phosphate levels (31). However, the benefit of calcium-based phosphate binders must be weighed against the possible adverse effects of hypercalcemia and/or vascular calcification. In a cohort of 16 young adult dialysis patients (aged 20-30 years old), Goodman et al found that $14(87.5 \%)$ had evidence of coronary artery calcification (compared to only 5\% of agematched controls), and that subjects with coronary artery calcification had higher calcium intake (nearly double that of subjects without calcification), higher serum phosphate, and 
higher calcium-phosphate cross-product (26). Subsequent studies have demonstrated the association between calcium intake and the development of vascular calcifications. In a study of adult patients with CKD stages 3 and 4, Hill et al found that calcium carbonate supplementation of $1500 \mathrm{mg}$ daily resulted in a positive calcium balance of $500 \mathrm{mg}$ daily (32). Moreover, calcium kinetics demonstrated a positive net bone balance that was less than the overall calcium balance, suggesting soft-tissue deposition (32). Similar balance studies in children with CKD are needed to define the optimal calcium intake for maximal bone growth.

At present, to avoid the development of cardiovascular calcifications, it is suggested that the total dose of elemental calcium provided by calcium-based phosphate binders and by dietary calcium not exceed twice the age-based AI or RDA for calcium (31). In infants, adequate intake (AI) of calcium is $210 \mathrm{mg}$ daily for ages 0-6 months, and $270 \mathrm{mg}$ daily for ages 7-12 months (29). The recommended dietary allowances (RDA) for older children are: $500 \mathrm{mg}$ daily for ages $1-3$ years, $800 \mathrm{mg}$ daily for ages $4-8$ years, and $1300 \mathrm{mg}$ daily for ages $9-18$ years (29). Furthermore, if hypercalcemia for age develops, then the calcium-based phosphate binder dose should be reduced. Age-specific normal ranges of blood total calcium and ionized calcium (iCa) are as follows: $0-5$ months $8.7-11.3 \mathrm{mg} / \mathrm{dL}$ (iCa $1.22-1.40$ $\mathrm{mmol} / \mathrm{L}$ ), 6-12 months $8.7-11.0 \mathrm{mg} / \mathrm{dL}$ (iCa $1.20-1.40 \mathrm{mmol} / \mathrm{L}$ ), $1-5$ years $9.4-10.8 \mathrm{mg} / \mathrm{dL}$ (iCa $1.22-1.32 \mathrm{mmol} / \mathrm{L}$ ), 6-12 years $9.4-10.3 \mathrm{mg} / \mathrm{dL}$ (iCa $1.15-1.32$ ), and $13-20$ years 8.8 $10.2 \mathrm{mg} / \mathrm{dL}$ (iCa $1.12-1.30 \mathrm{mmol} / \mathrm{L}$ ) (29).

Given concerns for hypercalcemia and vascular calcification with the use of calcium-based phosphate binders, alternative, non-calcium-based phosphate binders have been developed. These include sevelamer formulations, lanthanum, and iron-based compounds. Sevelamer hydrochloride (Renagel ${ }^{\circledR}$ ) and sevelamer carbonate (Renvela ${ }^{\circledR}$ ) are widely used in pediatric CKD. Sevelamer effectively controls hyperphosphatemia without increasing the incidence of hypercalcemia (33). Moreover, a recent meta-analysis of randomized controlled trials of calcium-based binders vs. non-calcium-based binders, which included 25 trials and approximately 8000 patients, found that the use of calcium-based binders resulted in higher mortality than sevelamer in particular and non-calcium-based binders in general (34). Lanthanum carbonate is another effective, non-calcium-based phosphate binder; however, lanthanum accumulates in bones (35) and, given concern for growth impairment in children, is not recommended for routine use in pediatric CKD.

Iron-based phosphate binders are intriguing given their theoretical ability to both bind enteral phosphorus and deliver iron. In a recent randomized trial of ferric citrate vs. active phosphate binder control in dialysis patients, Lewis et al showed that ferric citrate controlled phosphate levels as well as the active control, but also increased iron parameters, decreased the use of intravenous iron, decreased the use of erythropoiesis-stimulating agents, and blunted a decrease in hemoglobin (36). This medication has yet to be studied in the pediatric population.

Other non-calcium-based phosphate binders include aluminum and magnesium-based compounds. Aluminum containing compounds must be used with caution, given concern for aluminum accumulation in tissues, especially the bone and brain, possibly resulting in bone 
disease and encephalopathy. Therefore, in pediatric CKD, it is recommended that aluminumbased phosphate binders only be used in adolescent patients with serum phosphate $>7 \mathrm{mg} / \mathrm{dL}$ and only for one treatment course not to exceed 4-6 weeks (31). Importantly, in children receiving aluminum-based phosphate binders, concurrent use of citrate-based products should be avoided, as citrate enhances aluminum absorption, increasing the risk of aluminum toxicity (31). Magnesium-based compounds are not widely used, and may predispose patients to hypermagnesemia and diarrhea.

Enteral phosphate binders limit passive, paracellular phosphorus absorption. However, such binder-induced effects lead to upregulation of the intestinal sodium-phosphate Npt2b transporter, increasing active enteral phosphate absorption, offsetting some of the beneficial binder effect (37). In animal studies, compared to wild type mice with CKD, Npt2b knockout mice with CKD had significantly lower serum phosphate concentrations (and a blunted increase in FGF23) (37). Moreover, treating the Npt2b-deficient mice with sevelamer carbonate further reduced serum phosphate levels (37). In studies of adult (38) and pediatric (39) dialysis patients, the addition of nicotinamide—a vitamin B3 (niacin) derivative that inhibits Npt2b activity - to phosphate binder therapy effectively lowered serum phosphate levels. Furthermore, in adult CKD patients, with eGFR 30-74 ml/min/ $1.73 \mathrm{~m}^{2}$, Rao et al demonstrated that extended release niacin reduced both serum phosphate and FGF23 (40). Therefore, maximal suppression of enteral phosphorus absorption in CKD/ ESRD patients may possibly be best achieved using Npt $2 b$ inhibitors in combination with binders (41). However, further studies are needed to assess the impact of nicotinamide on phosphate control in children with CKD.

\section{Secondary hyperparathyroidism}

The mainstay of secondary hyperparathyroidism treatment is active vitamin D sterols (calcitriol or its analogs). In pediatric patients with CKD stages 2-4, it is recommended that active vitamin D sterols be initiated when serum PTH is above the target range for CKD stage, but only if $25(\mathrm{OH})$ vitamin D (25D) levels are sufficient ( $>30 \mathrm{ng} / \mathrm{mL}$ ), corrected total serum calcium is $<10 \mathrm{mg} / \mathrm{dL}$, and serum phosphate is within the age-appropriate range (31). The target range for PTH in CKD stages $2-3$ is $35-70 \mathrm{pg} / \mathrm{mL}$, and in CKD 4 is $70-110$ $\mathrm{pg} / \mathrm{mL}$ (29). In pediatric patients with CKD stage 5 (not on dialysis), it is recommended that active vitamin D sterols be initiated when PTH is $>300 \mathrm{pg} / \mathrm{mL}$ (31), but again only in the absence of hypercalcemia or hyperphosphatemia for age, with a goal of maintaining intact PTH levels in the range of approximately two to nine times the upper normal limit for the assay (2). However, the recommended PTH levels for pediatric ESRD patients remain controversial. In a large observational study of 890 pediatric peritoneal dialysis patients from 24 countries reported to the International Pediatric Peritoneal Dialysis Network Registry, clinical and radiological symptoms increased when PTH exceeded $300 \mathrm{pg} / \mathrm{ml}$, the risk of hypercalcemia increased with levels below $100 \mathrm{pg} / \mathrm{ml}$, and time-averaged PTH concentrations above $500 \mathrm{pg} / \mathrm{ml}$ were associated with impaired longitudinal growth (42). Based on these results, the authors recommended a PTH target range of 100-300 pg/ml. However, bone histomorphometry data was not available in this study, and the PTH assays were not standardized. 
Calcitriol is a commonly used active vitamin D sterol; however, it is associated with an increased risk of hypercalcemia and hyperphosphatemia. Therefore, vitamin D analogs with less calcemic and/or phosphatemic effects have been developed, including paricalcitol and doxercalciferol; however, regardless of the active vitamin D sterol used, serum calcium, phosphate, and PTH should be assessed frequently, and dosage changes made accordingly; algorithms exist regarding management of vitamin D sterols (31). Increased doses of noncalcium-based phosphate binders may prevent hyperphosphatemia, allowing for higher doses of vitamin D sterols to be used.

Despite the use of active vitamin D sterols to effectively control secondary hyperparathyroidism, bone disease continues to plague children and adolescents with CKD. Indeed, in a large cohort of adults who developed kidney disease in childhood, $37 \%$ had clinical symptoms of bone disease and $18 \%$ were disabled by bone disease (43).

Furthermore, vitamin D sterols may increase FGF23 levels. In a study of pediatric dialysis patients, Wesseling-Perry et al showed that both calcitriol and doxercalciferol suppressed PTH levels but increased circulating levels of FGF23 over fourfold, which was associated with a persistent mineralization defect (44). Although the mechanisms of skeletal mineralization are incompletely understood, FGF23 may inhibit mineralization $(45,46)$. Moreover, higher FGF23 levels are independently associated with increased mortality in the dialysis population $(47,48)$. Given the adverse clinical outcomes associated with higher FGF23 levels, further prospective studies are needed to better assess the long-term risks and benefits of vitamin D sterol treatment.

Another medication used for treatment of secondary hyperparathyroidism is cinacalcet, which acts as a calcimimetic by allosteric activation of the calcium-sensing receptor. Cinacalcet, which is commonly used in adult CKD/ESRD patients, effectively lowers serum PTH (49), as well as FGF23 (50). In pediatric dialysis patients, small studies demonstrated that cinacalcet acutely lowered PTH, lowered serum calcium, and was well-tolerated $(51,52)$. However, the long-term effects of cinacalcet in pediatric patients have not been studied and, as the calcium-sensing receptor is expressed on growth plate cartilage, the effects of cinacalcet on growth must be elucidated before cinacalcet use can be recommended in children.

Lastly, when secondary hyperparathyroidism is severe (persistent serum PTH >1000 pg/mL) and refractory to treatment with vitamin D sterols (or vitamin D sterol treatment is precluded by persistent hypercalcemia and/or hyperphosphatemia), it is suggested that subtotal parathyroidectomy be considered (31). Post-parathyroidectomy, serum calcium and phosphate must be monitored very closely, as "hungry bone syndrome," a condition characterized by acutely increased skeletal calcium and phosphate uptake, may cause marked hypocalcemia and/or hypophosphatemia. Treatment consists of large doses of active vitamin D and calcium. Phosphate supplementation may worsen hypocalcemia, and is generally not recommended unless serum phosphate is $<2.0 \mathrm{mg} / \mathrm{dL}$.

\section{Nutritional vitamin D supplementation}

As stated above, in pediatric patients with CKD stages 2-4, it is recommended that active vitamin D sterols be initiated when serum PTH is above the target range for CKD stage, but 
only if $25(\mathrm{OH})$ vitamin D (25D) levels are sufficient ( $>30 \mathrm{ng} / \mathrm{mL})$. If serum PTH is above the target range for CKD stage, but 25D levels are insufficient $(<30 \mathrm{ng} / \mathrm{mL})$, then it is suggested to first replete nutritional 25D stores with vitamin $\mathrm{D}_{2}$ (ergocalciferol) (31). Indeed, Shroff et al demonstrated that ergocalciferol treatment delays the development of secondary hyperparathyroidism in children with early CKD (53). As with active vitamin D sterols, once ergocalciferol supplementation has been initiated, serum calcium and phosphate should be monitored frequently. If hypercalcemia develops, then vitamin D supplementation should be discontinued. If hyperphosphatemia develops, and nutritional vitamin D supplementation is still required, then intensified phosphate control may allow for continued vitamin D treatment. In ESRD, with less functional renal parenchyma, there is less renal conversion of $25 \mathrm{D}$ to active $1,25 \mathrm{D}$, and thus more reliance on extra-renal 25D activation. In these patients, the benefit of nutritional vitamin D supplementation is less clear. Thus, there is controversy regarding the effectiveness of nutritional vitamin D supplementation in advanced CKD (54).

\section{Fibroblast growth factor 23}

In adult (19) and pediatric (20) CKD-MBD, elevated FGF23 levels are the first observed biochemical abnormality (Figure 1A). Increased FGF23 levels help to maintain normophosphatemia until late in the CKD course; however, higher FGF23 levels are associated with the development of left ventricular hypertrophy (55), CKD progression (48,56,57; Figure 1B), and mortality $(47,48)$. Currently, there are no specific treatments focused on decreasing FGF23 levels and, as mentioned above, active vitamin D sterol treatment of secondary hyperparathyroidism may have the adverse effect of increasing FGF23. One possible approach to blunting the rise of FGF23 levels in CKD, and possibly decreasing FGF23-associated morbidity and mortality, is early lowering of phosphate levels. To test this hypothesis, the CKD Optimal Management with BInders and NicotinamidE (COMBINE) study has been initiated (41). This randomized clinical trial will assess, in predialysis CKD patients, whether the early use of phosphate binders, with or without concurrent blockade of the intestinal sodium-phosphate co-transporter NPT2b, decreases serum phosphate and FGF23 concentrations and improves surrogate measures of cardiovascular disease, CKD progression, and inflammation. If the hypotheses of the COMBINE study are confirmed - that early phosphate binder therapy with or without NPT2b blockade improves the outcome measures-then the results may provide the basis for future clinical trials assessing the effects of such novel CKD-MBD treatment paradigms on hard clinical endpoints.

In addition to phosphate and 1,25D, other non-mineral metabolism factors have been recently identified as important determinants of FGF23 production. Notably, inflammation $(58,59)$ and iron deficiency $(59-61)$ may increase FGF23 production in CKD. The identification of such novel factors not only helps to better elucidate important aspects of FGF23 regulation, but may also inform new therapeutic strategies to lower pathologically high FGF23 levels in CKD. 


\section{Acknowledgments}

The authors' work has been supported by an NIH/NIDDK K08 Mentored Clinical Scientist Research Career Development Award (DK111980, to MRH), an NIH/NICHD K12 Child Health Research Career Development Award (HD034610, to MRH), a UCLA Clinical and Translational Science Institute \& UCLA Children's Discovery and Innovation Institute Children's Health Team Science Award (to MRH and IBS), an NIH/NIDDK R01 grant (DK35423, to IBS), and an NIH/NIDDK U34 grant (DK104619, to IBS).

\section{References}

Papers of particular interest, published recently, have been highlighted as:

- Of importance

•• Of major importance

1. Moe S, Drüeke T, Cunningham J, Goodman W, Martin K, Olgaard K, Ott S, Sprague S, Lameire N, Eknoyan G. Kidney Disease: Improving Global Outcomes (KDIGO). Definition, evaluation, and classification of renal osteodystrophy: a position statement from Kidney Disease: Improving Global Outcomes (KDIGO). Kidney Int. 2006 Jun; 69(11):1945-53. [PubMed: 16641930]

2. Kidney Disease: Improving Global Outcomes (KDIGO) CKD-MBD Work Group. KDIGO clinical practice guideline for the diagnosis, evaluation, prevention, and treatment of Chronic Kidney Disease-Mineral and Bone Disorder (CKD-MBD). Kidney Int Suppl. 2009 Aug.(113):S1-130.

3. Seikaly MG, Salhab N, Gipson D, Yiu V, Stablein D. Stature in children with chronic kidney disease: analysis of NAPRTCS database. Pediatr Nephrol. 2006 Jun; 21(6):793-9. [PubMed: 16583244]

4. Denburg MR, Kumar J, Jemielita T, Brooks ER, Skversky A, Portale AA, Salusky IB, Warady BA, Furth SL, Leonard MB. Fracture Burden and Risk Factors in Childhood CKD: Results from the CKiD Cohort Study. J Am Soc Nephrol. 2016 Feb; 27(2):543-50. [PubMed: 26139439]

5. Mehls O, Ritz E, Krempien B, Gilli G, Link K, Willich E, Schärer K. Slipped epiphyses in renal osteodystrophy. Arch Dis Child. 1975 Jul; 50(7):545-54. [PubMed: 1167068]

6. Bakkaloglu SA, Wesseling-Perry K, Pereira RC, Gales B, Wang HJ, Elashoff RM, Salusky IB. Value of the new bone classification system in pediatric renal osteodystrophy. Clin J Am Soc Nephrol. 2010 Oct; 5(10):1860-6. [PubMed: 20634327]

7. Wesseling-Perry K, Pereira RC, Sahney S, Gales B, Wang HJ, Elashoff R, Jüppner H, Salusky IB. Calcitriol and doxercalciferol are equivalent in controlling bone turnover, suppressing parathyroid hormone, and increasing fibroblast growth factor-23 in secondary hyperparathyroidism. Kidney Int. 2011 Jan; 79(1):112-9. [PubMed: 20861820]

8. Wesseling-Perry K, Pereira RC, Tseng CH, Elashoff R, Zaritsky JJ, Yadin O, Sahney S, Gales B, Jüppner H, Salusky IB. Early skeletal and biochemical alterations in pediatric chronic kidney disease. Clin J Am Soc Nephrol. 2012 Jan; 7(1):146-52. [PubMed: 22052943]

9. Weber LT, Mehls O. Limitations of dual x-ray absorptiometry in children with chronic kidney disease. Pediatr Nephrol. 2010 Jan; 25(1):3-5. [PubMed: 19603191]

10. Bacchetta J, Harambat J, Cochat P, Salusky IB, Wesseling-Perry K. The consequences of chronic kidney disease on bone metabolism and growth in children. Nephrol Dial Transplant. 2012 Aug; 27(8):3063-71. [PubMed: 22851629]

11. Gordon CM, Leonard MB, Zemel BS. International Society for Clinical Densitometry. 2013 Pediatric Position Development Conference: executive summary and reflections. J Clin Densitom. 2014 Apr-Jun;17(2):219-24. [PubMed: 24657108]

12. Gilsanz V. Bone density in children: a review of the available techniques and indications. Eur J Radiol. 1998 Jan; 26(2):177-82. [PubMed: 9518226]

13. Lima EM, Goodman WG, Kuizon BD, Gales B, Emerick A, Goldin J, Salusky IB. Bone density measurements in pediatric patients with renal osteodystrophy. Pediatr Nephrol. 2003 Jun; 18(6): 554-9. [PubMed: 12712376] 
14. Denburg MR, Tsampalieros AK, de Boer IH, Shults J, Kalkwarf HJ, Zemel BS, Foerster D, Stokes D, Leonard MB. Mineral metabolism and cortical volumetric bone mineral density in childhood chronic kidney disease. J Clin Endocrinol Metab. 2013 May; 98(5):1930-8. [PubMed: 23547048]

15. Gkogka C, Christoforidis A, Printza N, Kollios K, Kazantzidou E, Papachristou F. Longitudinal assessment of bone quality in pediatric patients with chronic kidney disease in relation to treatment modality. J Bone Miner Metab. 2015 May; 33(3):303-10. [PubMed: 24859053]

•16. Isakova T, Wahl P, Vargas GS, Gutiérrez OM, Scialla J, Xie H, Appleby D, Nessel L, Bellovich K, Chen J, Hamm L, Gadegbeku C, Horwitz E, Townsend RR, Anderson CA, Lash JP, Hsu CY, Leonard MB, Wolf M. Fibroblast growth factor 23 is elevated before parathyroid hormone and phosphate in chronic kidney disease. Kidney Int. 2011 Jun; 79(12):1370-8. This study demonstrates that elevated FGF23 levels are the first observed biochemical abnormality in adult CKD-MBD. [PubMed: 21389978]

-17. Portale AA, Wolf M, Jüppner H, Messinger S, Kumar J, Wesseling-Perry K, Schwartz GJ, Furth SL, Warady BA, Salusky IB. Disordered FGF23 and mineral metabolism in children with CKD. Clin J Am Soc Nephrol. 2014 Feb; 9(2):344-53. This study demonstrates that elevated FGF23 levels are the first observed biochemical abnormality in pediatric CKD-MBD. [PubMed: 24311704]

18. Saito H, Maeda A, Ohtomo S, Hirata M, Kusano K, Kato S, Ogata E, Segawa H, Miyamoto K, Fukushima N. Circulating FGF-23 is regulated by 1alpha,25-dihydroxyvitamin D3 and phosphorus in vivo. J Biol Chem. 2005 Jan 28; 280(4):2543-9. [PubMed: 15531762]

19. Antoniucci DM, Yamashita T, Portale AA. Dietary phosphorus regulates serum fibroblast growth factor-23 concentrations in healthy men. J Clin Endocrinol Metab. 2006 Aug; 91(8):3144-9. [PubMed: 16735491]

20. Portale AA, Booth BE, Halloran BP, Morris RC Jr. Effect of dietary phosphorus on circulating concentrations of 1,25-dihydroxyvitamin $\mathrm{D}$ and immunoreactive parathyroid hormone in children with moderate renal insufficiency. J Clin Invest. 1984 Jun; 73(6):1580-9. [PubMed: 6547151]

21. Shimada T, Kakitani M, Yamazaki Y, Hasegawa H, Takeuchi Y, Fujita T, Fukumoto S, Tomizuka K, Yamashita T. Targeted ablation of Fgf23 demonstrates an essential physiological role of FGF23 in phosphate and vitamin D metabolism. J Clin Invest. 2004 Feb; 113(4):561-8. [PubMed: 14966565]

22. Bai XY, Miao D, Goltzman D, Karaplis AC. The autosomal dominant hypophosphatemic rickets R176Q mutation in fibroblast growth factor 23 resists proteolytic cleavage and enhances in vivo biological potency. J Biol Chem. 2003 Mar 14; 278(11):9843-9. [PubMed: 12519781]

23. Naveh-Many T, Marx R, Keshet E, Pike JW, Silver J. Regulation of 1,25-dihydroxyvitamin D3 receptor gene expression by 1,25-dihydroxyvitamin D3 in the parathyroid in vivo. J Clin Invest. 1990 Dec; 86(6):1968-75. [PubMed: 2174913]

24. Dhayat NA, Ackermann D, Pruijm M, Ponte B, Ehret G, Guessous I, Leichtle AB, Paccaud F, Mohaupt M, Fiedler GM, Devuyst O, Pechère-Bertschi A, Burnier M, Martin PY, Bochud M, Vogt B, Fuster DG. Fibroblast growth factor 23 and markers of mineral metabolism in individuals with preserved renal function. Kidney Int. 2016 Sep; 90(3):648-57. [PubMed: 27370409]

25. Naveh-Many T, Silver J. The Pas de Trois of Vitamin D, FGF23, and PTH. J Am Soc Nephrol. 2016 Nov 2 ..

26. Goodman WG, Goldin J, Kuizon BD, Yoon C, Gales B, Sider D, Wang Y, Chung J, Emerick A, Greaser L, Elashoff RM, Salusky IB. Coronary-artery calcification in young adults with end-stage renal disease who are undergoing dialysis. N Engl J Med. 2000 May 18; 342(20):1478-83. [PubMed: 10816185]

27. Hruska KA, Seifert M, Sugatani T. Pathophysiology of the chronic kidney disease-mineral bone disorder. Curr Opin Nephrol Hypertens. 2015 Jul; 24(4):303-9. [PubMed: 26050115]

28. Fang Y, Ginsberg C, Seifert M, Agapova O, Sugatani T, Register TC, Freedman BI, MonierFaugere MC, Malluche H, Hruska KA. CKD-induced wingless/integration1 inhibitors and phosphorus cause the CKD-mineral and bone disorder. J Am Soc Nephrol. 2014 Aug; 25(8):176073. [PubMed: 24578135]

29. National Kidney Foundation K/DOQI Workgroup. K/DOQI clinical practice guidelines for nutrition in children with chronic kidney disease. Am J Kidney Dis. 2009; 53:S1-123. 
30. Portale AA, Booth BE, Halloran BP, Morris RC Jr. Effect of dietary phosphorus on circulating concentrations of 1,25-dihydroxyvitamin $\mathrm{D}$ and immunoreactive parathyroid hormone in children with moderate renal insufficiency. J Clin Invest. 1984 Jun; 73(6):1580-9. [PubMed: 6547151]

31. National Kidney Foundation K/DOQI Workgroup. K/DOQI clinical practice guidelines for bone metabolism and disease in children with chronic kidney disease. Am J Kidney Dis. 2005; 46:S1121.

32. Hill KM, Martin BR, Wastney ME, McCabe GP, Moe SM, Weaver CM, Peacock M. Oral calcium carbonate affects calcium but not phosphorus balance in stage 3-4 chronic kidney disease. Kidney Int. 2013 May; 83(5):959-66. [PubMed: 23254903]

33. Bleyer AJ, Burke SK, Dillon M, Garrett B, Kant KS, Lynch D, Rahman SN, Schoenfeld P, Teitelbaum I, Zeig S, Slatopolsky E. A comparison of the calcium-free phosphate binder sevelamer hydrochloride with calcium acetate in the treatment of hyperphosphatemia in hemodialysis patients. Am J Kidney Dis. 1999 Apr; 33(4):694-701. [PubMed: 10196011]

34. Sekercioglu N, Thabane L, Díaz Martínez JP, Nesrallah G, Longo CJ, Busse JW, Akhtar-Danesh N, Agarwal A, Al-Khalifah R, Iorio A, Guyatt GH. Comparative Effectiveness of Phosphate Binders in Patients with Chronic Kidney Disease: A Systematic Review and Network Meta-Analysis. PLoS One. 2016 Jun 8.11(6):e0156891. [PubMed: 27276077]

35. Drüeke TB. Lanthanum carbonate as a first-line phosphate binder: the "cons". Semin Dial. 2007 Jul-Aug;20(4):329-32. [PubMed: 17635823]

36. Lewis JB, Sika M, Koury MJ, Chuang P, Schulman G, Smith MT, Whittier FC, Linfert DR, Galphin CM, Athreya BP, Nossuli AK, Chang IJ, Blumenthal SS, Manley J, Zeig S, Kant KS, Olivero JJ, Greene T, Dwyer JP. Collaborative Study Group. Ferric citrate controls phosphorus and delivers iron in patients on dialysis. J Am Soc Nephrol. 2015 Feb; 26(2):493-503. [PubMed: 25060056]

37. Schiavi SC, Tang W, Bracken C, O’Brien SP, Song W, Boulanger J, Ryan S, Phillips L, Liu S, Arbeeny C, Ledbetter S, Sabbagh Y. Npt2b deletion attenuates hyperphosphatemia associated with CKD. J Am Soc Nephrol. 2012 Oct; 23(10):1691-700. [PubMed: 22859851]

38. Cheng SC, Young DO, Huang Y, Delmez JA, Coyne DW. A randomized, double-blind, placebocontrolled trial of niacinamide for reduction of phosphorus in hemodialysis patients. Clin J Am Soc Nephrol. 2008 Jul; 3(4):1131-8. [PubMed: 18385391]

39. El Borolossy R, El Wakeel LM, El Hakim I, Sabri N. Efficacy and safety of nicotinamide in the management of hyperphosphatemia in pediatric patients on regular hemodialysis. Pediatr Nephrol. 2016 Feb; 31(2):289-96. [PubMed: 26420678]

40. Rao M, Steffes M, Bostom A, Ix JH. Effect of niacin on FGF23 concentration in chronic kidney disease. Am J Nephrol. 2014; 39(6):484-90. [PubMed: 24854458]

41. Isakova T, Ix JH, Sprague SM, Raphael KL, Fried L, Gassman JJ, Raj D, Cheung AK, Kusek JW, Flessner MF, Wolf M, Block GA. Rationale and Approaches to Phosphate and Fibroblast Growth Factor 23 Reduction in CKD. J Am Soc Nephrol. 2015 Oct; 26(10):2328-39. [PubMed: 25967123]

42. Borzych D, Rees L, Ha IS, Chua A, Valles PG, Lipka M, Zambrano P, Ahlenstiel T, Bakkaloglu SA, Spizzirri AP, Lopez L, Ozaltin F, Printza N, Hari P, Klaus G, Bak M, Vogel A, Ariceta G, Yap HK, Warady BA, Schaefer F. International Pediatric PD Network (IPPN). The bone and mineral disorder of children undergoing chronic peritoneal dialysis. Kidney Int. 2010 Dec; 78(12):1295304. [PubMed: 20811335]

43. Groothoff JW, Offringa M, Van Eck-Smit BL, Gruppen MP, Van De Kar NJ, Wolff ED, Lilien MR, Davin JC, Heymans HS, Dekker FW. Severe bone disease and low bone mineral density after juvenile renal failure. Kidney Int. 2003 Jan; 63(1):266-75. [PubMed: 12472792]

44. Wesseling-Perry K, Pereira RC, Sahney S, Gales B, Wang HJ, Elashoff R, Jüppner H, Salusky IB. Calcitriol and doxercalciferol are equivalent in controlling bone turnover, suppressing parathyroid hormone, and increasing fibroblast growth factor-23 in secondary hyperparathyroidism. Kidney Int. 2011 Jan; 79(1):112-9. [PubMed: 20861820]

45. Wang H, Yoshiko Y, Yamamoto R, Minamizaki T, Kozai K, Tanne K, Aubin JE, Maeda N. Overexpression of fibroblast growth factor 23 suppresses osteoblast differentiation and matrix mineralization in vitro. J Bone Miner Res. 2008 Jun; 23(6):939-48. [PubMed: 18282132] 
46. Shalhoub V, Ward SC, Sun B, Stevens J, Renshaw L, Hawkins N, Richards WG. Fibroblast growth factor 23 (FGF23) and alpha-klotho stimulate osteoblastic MC3T3.E1 cell proliferation and inhibit mineralization. Calcif Tissue Int. 2011 Aug; 89(2):140-50. [PubMed: 21633782]

••47. Gutiérrez OM, Mannstadt M, Isakova T, Rauh-Hain JA, Tamez H, Shah A, Smith K, Lee H, Thadhani R, Jüppner H, Wolf M. Fibroblast growth factor 23 and mortality among patients undergoing hemodialysis. N Engl J Med. 2008 Aug 7; 359(6):584-92. This study demonstrates that elevated FGF23 levels are independently associated with mortality in CKD patients. [PubMed: 18687639]

••48. Isakova T, Xie H, Yang W, Xie D, Anderson AH, Scialla J, Wahl P, Gutiérrez OM, Steigerwalt S, He J, Schwartz S, Lo J, Ojo A, Sondheimer J, Hsu CY, Lash J, Leonard M, Kusek JW, Feldman HI, Wolf M. Chronic Renal Insufficiency Cohort (CRIC) Study Group. Fibroblast growth factor 23 and risks of mortality and end-stage renal disease in patients with chronic kidney disease. JAMA. 2011 Jun 15; 305(23):2432-9. This study demonstrates that elevated FGF23 levels are independently associated with progression to ESRD and mortality in CKD patients. [PubMed: 21673295]

49. Chertow GM, Block GA, Correa-Rotter R, Drüeke TB, Floege J, Goodman WG, Herzog CA, Kubo Y, London GM, Mahaffey KW, Mix TC, Moe SM, Trotman ML, Wheeler DC, Parfrey PS. EVOLVE Trial Investigators. Effect of cinacalcet on cardiovascular disease in patients undergoing dialysis. N Engl J Med. 2012 Dec 27; 367(26):2482-94. [PubMed: 23121374]

50. Moe SM, Chertow GM, Parfrey PS, Kubo Y, Block GA, Correa-Rotter R, Drüeke TB, Herzog CA, London GM, Mahaffey KW, Wheeler DC, Stolina M, Dehmel B, Goodman WG, Floege J. Evaluation of Cinacalcet $\mathrm{HCl}$ Therapy to Lower Cardiovascular Events (EVOLVE) Trial Investigators. Cinacalcet, Fibroblast Growth Factor-23, and Cardiovascular Disease in Hemodialysis: The Evaluation of Cinacalcet $\mathrm{HCl}$ Therapy to Lower Cardiovascular Events (EVOLVE) Trial. Circulation. 2015 Jul 7; 132(1):27-39. [PubMed: 26059012]

51. Muscheites J, Wigger M, Drueckler E, Fischer DC, Kundt G, Haffner D. Cinacalcet for secondary hyperparathyroidism in children with end-stage renal disease. Pediatr Nephrol. 2008 Oct; 23(10): 1823-9. [PubMed: 18504621]

52. Padhi D, Langman CB, Fathallah-Shaykh S, Warady BA, Salusky IB, Lee E, Wang C, Posvar E. An open-label study to evaluate a single-dose of cinacalcet in pediatric dialysis subjects. Pediatr Nephrol. 2012 Oct; 27(10):1953-9. [PubMed: 22639045]

53. Shroff R, Wan M, Gullett A, Ledermann S, Shute R, Knott C, Wells D, Aitkenhead H, Manickavasagar B, van't Hoff W, Rees L. Ergocalciferol supplementation in children with CKD delays the onset of secondary hyperparathyroidism: a randomized trial. Clin J Am Soc Nephrol. 2012 Feb; 7(2):216-23. [PubMed: 22266572]

54. Zoccali C, Mallamaci F. Moderator's view: Vitamin D deficiency treatment in advanced chronic kidney disease: a close look at the emperor's clothes. Nephrol Dial Transplant. 2016 May; 31(5): 714-6. [PubMed: 27190394]

••55. Faul C, Amaral AP, Oskouei B, Hu MC, Sloan A, Isakova T, Gutiérrez OM, Aguillon-Prada R, Lincoln J, Hare JM, Mundel P, Morales A, Scialla J, Fischer M, Soliman EZ, Chen J, Go AS, Rosas SE, Nessel L, Townsend RR, Feldman HI, St John Sutton M, Ojo A, Gadegbeku C, Di Marco GS, Reuter S, Kentrup D, Tiemann K, Brand M, Hill JA, Moe OW, Kuro-O M, Kusek JW, Keane MG, Wolf M. FGF23 induces left ventricular hypertrophy. J Clin Invest. 2011 Nov; 121(11):4393-408. This study demonstrates that FGF23 directly induces left ventricular hypertrophy in an animal model. [PubMed: 21985788]

56. Fliser D, Kollerits B, Neyer U, Ankerst DP, Lhotta K, Lingenhel A, Ritz E, Kronenberg F, Kuen E, König P, Kraatz G, Mann JF, Müller GA, Köhler H, Riegler P. MMKD Study Group. Fibroblast growth factor 23 (FGF23) predicts progression of chronic kidney disease: the Mild to Moderate Kidney Disease (MMKD) Study. J Am Soc Nephrol. 2007 Sep; 18(9):2600-8. [PubMed: 17656479]

57. Portale AA, Wolf MS, Messinger S, Perwad F, Jüppner H, Warady BA, Furth SL, Salusky IB. Fibroblast Growth Factor 23 and Risk of CKD Progression in Children. Clin J Am Soc Nephrol. 2016 Nov 7; 11(11):1989-1998. [PubMed: 27561289]

58. Munoz Mendoza J, Isakova T, Ricardo AC, Xie H, Navaneethan SD, Anderson AH, Bazzano LA, Xie D, Kretzler M, Nessel L, Hamm LL, Negrea L, Leonard MB, Raj D, Wolf M. Chronic Renal 
Insufficiency Cohort. Fibroblast growth factor 23 and Inflammation in CKD. Clin J Am Soc Nephrol. 2012 Jul; 7(7):1155-62. [PubMed: 22554719]

59. David V, Martin A, Isakova T, Spaulding C, Qi L, Ramirez V, Zumbrennen-Bullough KB, Sun CC, Lin HY, Babitt JL, Wolf M. Inflammation and functional iron deficiency regulate fibroblast growth factor 23 production. Kidney Int. 2016 Jan; 89(1):135-46. [PubMed: 26535997]

60. Farrow EG, Yu X, Summers LJ, Davis SI, Fleet JC, Allen MR, Robling AG, Stayrook KR, Jideonwo V, Magers MJ, Garringer HJ, Vidal R, Chan RJ, Goodwin CB, Hui SL, Peacock M, White KE. Iron deficiency drives an autosomal dominant hypophosphatemic rickets (ADHR) phenotype in fibroblast growth factor-23 (Fgf23) knock-in mice. Proc Natl Acad Sci U S A. 2011 Nov 15; 108(46):E1146-55. [PubMed: 22006328]

61. Hanudel MR, Chua K, Rappaport M, Gabayan V, Valore E, Goltzman D, Ganz T, Nemeth E, Salusky IB. Effects of dietary iron intake and chronic kidney disease on fibroblast growth factor 23 metabolism in wild-type and hepcidin knockout mice. Am J Physiol Renal Physiol. 2016 Dec 1; 311(6):F1369-F1377. [PubMed: 27733366] 

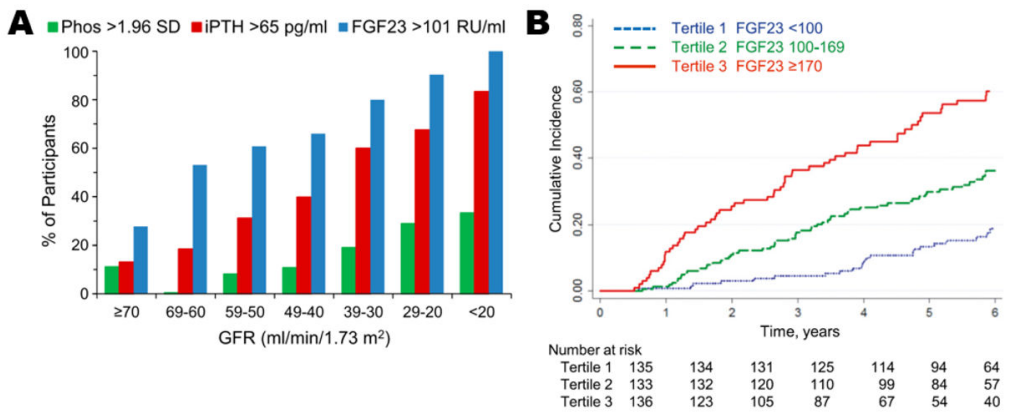

Figure 1.

In pediatric chronic kidney disease (CKD) patients, elevated fibroblast growth factor 23 (FGF23) levels are observed very early in the CKD course (Fig. 1A; 17) and are associated with CKD progression (defined as either dialysis initiation, kidney transplantation, or a 50\% reduction in glomerular filtration rate (GFR) from baseline) (Fig. 1B; 57). The association between higher FGF23 levels and CKD progression persists after multivariable adjustment for baseline GFR, proteinuria, blood pressure, glomerular vs. non-glomerular disease, and medication use (angiotensin converting enzyme inhibitors/angiotensin-receptor blockers, vitamin D analogs, and phosphate binders) (57). Used with permission from the American Society of Nephrology. 